IZA DP No. 9713

The Economics of Healthy Ageing in China

Almas Heshmati

February 2016 


\title{
The Economics of Healthy Ageing in China
}

\author{
Almas Heshmati \\ Sogang University \\ and IZA
}

\section{Discussion Paper No. 9713 \\ February 2016}

\author{
IZA \\ P.O. Box 7240 \\ 53072 Bonn \\ Germany \\ Phone: +49-228-3894-0 \\ Fax: +49-228-3894-180 \\ E-mail: iza@iza.org
}

Any opinions expressed here are those of the author(s) and not those of IZA. Research published in this series may include views on policy, but the institute itself takes no institutional policy positions. The IZA research network is committed to the IZA Guiding Principles of Research Integrity.

The Institute for the Study of Labor (IZA) in Bonn is a local and virtual international research center and a place of communication between science, politics and business. IZA is an independent nonprofit organization supported by Deutsche Post Foundation. The center is associated with the University of Bonn and offers a stimulating research environment through its international network, workshops and conferences, data service, project support, research visits and doctoral program. IZA engages in (i) original and internationally competitive research in all fields of labor economics, (ii) development of policy concepts, and (iii) dissemination of research results and concepts to the interested public.

IZA Discussion Papers often represent preliminary work and are circulated to encourage discussion. Citation of such a paper should account for its provisional character. A revised version may be available directly from the author. 
IZA Discussion Paper No. 9713

February 2016

\section{ABSTRACT}

\section{The Economics of Healthy Ageing in China}

Healthy ageing is a challenge for many countries with significant shares of elderly people. Literature refers to China's ageing population as a ticking time bomb which paradoxically is both a challenge and an opportunity for the country. Health is considered an important determinant of economic growth and competitiveness. The health of the elderly population determines its need for resources and care. Thus, investing in healthy ageing contributes to economic and social well-being. This study is a review of literature on the social and economic aspects of healthy ageing. It summarizes alternative approaches presented in literature to ease pressures of a rapidly growing ageing population. The main focus is on strategies for healthy ageing, policy practices and measures, organization, finances and manpower resources to promote healthy ageing in China. Up-to-date theories and methods applied to household surveys and population statistics are used to quantify the problem, resource requirements and estimating the social and economic benefits of having policies and measures for healthy ageing. Conclusions are drawn with respect to conditions of healthy ageing in China and about the state policy in this regard.

JEL Classification: $\quad H 75, I 15, I 18, I 38$, P36

Keywords: healthy ageing, ageing in China, active ageing, challenges and opportunities, economics of healthy ageing

Corresponding author:

Almas Heshmati

Department of Economics

Sogang University

Baekbeom-ro (Sinsu-dong \#1), Mapo-gu

Seoul 121-742

Republic of Korea

E-mail: heshmati@sogang.ac.kr 


\section{Introduction}

The need for healthy ageing is a challenge for all nations, and in particular for large countries like China and India with more elderly people than any other country in the world. According to the World Health Organization (WHO), health refers to physical, mental and social wellbeing. Healthy ageing is defined as developing and maintaining optimal health and functions in older adults in a society. This is most likely to be achieved when communities are safe, there is active promotion of health and well-being, the elderly use health services and there are various community programs to prevent or minimize the prevalence of various diseases. A policy for active ageing is a public policy that aims to extend healthy life expectancies and quality of life for all people as they age.

Ageing will have an enormous impact on Indian and Chinese societies. Literature refers to China's ageing population as a ticking time bomb. Some look at growing ageing in China both as a challenge and also as an opportunity to influence the trend of ageing in the desired direction. Health is also considered an important determinant of economic growth, social well-being and competitiveness of nations. The health of the elderly population determines its need for resources and care. This is particularly the case in societies with inclusive welfare service provisions. Thus, investing in healthy ageing contributes positively to labor supply and decreasing the likelihood of costly early retirement. It is crucial for governments, in particular the Chinese government, to plan their ageing related policies and allocating health and welfare resources adequately for the future.

In addition to positive health, labor supply and reduced retirement and sick-leave costs there are some forces which impact healthy ageing in China both positively and negatively. The positive forces include growth in the economy, higher educational advancements, technological development, increasing detection and treatment of diseases and the availability of health insurance and health services. Furthermore, the age gap or inequality in longevity has been reduced in society. The negative forces center on disturbing trends in personal health behaviors such as growing rates of smoking, obesity and pollution. Other changes are related to an increase in fertility rates and rural-to-urban labor migration separating elderly parents from their children who are traditionally expected to take care of the old.

This study is a review of literature on the social and economic aspects of healthy ageing. It summarizes identified alternative approaches presented in literature to ease the pressures from a rapidly growing ageing population. The main focus is on strategies for healthy ageing, policy practices and measures, organization and finances and manpower resources employed to promote healthy ageing. Up-to-date theories and methods applied to household surveys and population statistics are used to quantify the problem, resource requirements and for estimating social and economic benefits of healthy ageing policies and measures. Conclusions are drawn with respect to policy and the conditions of healthy ageing in China.

The rest of the study is divided as follows: Section 2 presents a review of literature with specific focus on the determinants and evolution of healthy ageing, health inequalities in a 'fair society' and measurements of healthy ageing. Section 3 gives the state of ageing conditions in Europe, USA, China, India and other countries. The next section discusses the 
economics and policies of healthy ageing with emphasis on urban conditions. Various public investment programs in building infrastructure as well as measures such as diet and other preventive factors supporting healthy ageing are discussed in Section 5. The next section discusses gained experience in the form of optimal healthy ageing for China and accompanied policy recommendations. The final section summarizes the important findings and provides conclusions.

\section{Literature on Healthy Ageing}

This section provides a review of literature on healthy ageing. Among other things, it discusses the evolution of healthy ageing and research on ageing and ageing-related topics, a strategic review of health inequalities, fair society and the measurement of healthy ageing.

\subsection{The evolution of healthy ageing}

As a result of developments in technology and education, average life expectancy is increasing. Radical changes in this regard are illustrated by Rasmussen et al. (2011) in the form of male-female population age demographics in rural-urban populations in 1975 and 2005 for less and more developed nations. They see the general increase in mean age of the population regardless of location and level of human development as a phenomenon that will bring social, political, economic and biomedical challenges for current and future generations worldwide. A series of International Alliance of Research Universities (IARU) ${ }^{1}$ congresses on 'Ageing, Longevity and Health' is held in Copenhagen to attract researchers with interest in ageing and age-related topics. Major shifts have been observed in demographics of urban populations in more developed nations in 2005 as compared to 1975.

Rasmussen et al. (2011) highlight the outcomes of recent research on ageing-related topics presented at the congress. The report on the meeting illustrates the situation on the evolution of population age structures in urban and rural regions by levels of development over the last 50 years and projections for future changes in population age demographics. They predict that by 2050, 33 per cent of developed countries and 22 per cent of developing countries' populations will be over 60 years. This represents a doubling of the elderly population worldwide. To meet this challenge, researchers use a multifaceted interdisciplinary approach. One of the aims of this approach is developing therapeutic interventions tested in elderly populations to investigate enhancements in the quality of human life while increasing its length, improving the ability to understand human biology, developing cost effective and efficient methods and reaching consensus on how to allocate limited resources to meet the competing medical, social and economic needs and priorities of different age groups.

\footnotetext{
${ }^{1}$ IARU is an alliance of ten leading research universities which are collaborating on activities related to ageing challenges with global scope and implications for society. The program on 'Ageing, Longevity and Health' is a core element of IARU's vision and activities.
} 


\subsection{Health inequalities and healthy ageing}

Inequality can have many dimensions. Income inequality is the most commonly studied dimension. Inequalities in assets, health, life expectancy, education, well-being, opportunities, gender gap and safety are among the other studied dimensions. Here the focus is on the effects of health inequality and healthy ageing in a fair society context.

Britain has commissioned a number of inquiries into health, including the Black Report in 1980, the Ashton Report in 1998 and the Marmot Review released in 2010. The Marmot Review is a strategic review of health inequalities in England post-2010. It was commissioned following the release of the WHO commission report in 2008 (CSDH, 2008) on social determinants of health. It is an independent report with the aim of consolidating evidence on health inequalities and developing the most effective evidence-based strategies for reducing health inequalities in England. The Review's four key tasks include: (i) identifying evidence to inform policy and actions to reduce health inequalities, (ii) demonstrating how the evidence can be translated into practice, (iii) advising on objectives and measures to reduce mortality and increasing life expectancy, and (iv) contributing to the development of a health inequality reduction strategy.

An overview of the reflections on the findings of the report putting fairness at the heart of policymaking is provided in Marmot and Bell (2012) and in Marmot et al. (2010). The Marmot Review's (Department of Health, 2010) key findings are presented in Subramanyan et al. (2010) under nine points: (i) reducing inequalities is about fairness in society to increase extra years of life, (ii) there is a social gradient in health which requires actions to reduce it, (iii) reduction of health inequalities requires action across the social determinants of health, (iv) actions should be universal with scale and intensity towards the disadvantaged, (v) actions reducing health inequalities will accompany economic benefits, (vi) tackling health inequalities and climate change must go together, (vii) reducing health inequalities will require preventive actions on several objectives, (viii) establishing partnership in delivery of health equity by public, private and communities, and (ix) effective local delivery requires effective participatory decision-making.

Chandra and Vogl (2010) discuss the Marmot Review and its prescriptions from the perspective of economists. In their comments they focus on leaping over shorter distances between accumulated knowledge of causal systems and economically implementable policies.

\subsection{Measurement of healthy ageing}

Several techniques have been developed to measure healthy ageing. The progress is along both single and multidimensional measures with differing focus on biological ageing, predictions of longevity and genetic healthy ageing.

Biological ageing is a complex process. Lara et al. (2013) do not find a single, simple and reliable measure of how an individual is ageing in a healthy manner. The authors use the healthy ageing phenotype (HAP) in large literature on lifestyle-based intervention studies. Their aim is identifying the key features of healthy ageing and identifying or developing 
tools for measuring these features. The selected domains include physiological and metabolic health, physical capabilities, cognitive functions, social well-being and psychological and subjective well-being. These are expected to provide a holistic characterization of the healthy ageing phenotype. The authors propose a panel of outcome measures which could be deployed in community-based lifestyle intervention studies. The evidence base for selecting measurement domains seems to be less well developed in some areas which have implications for identifying appropriate measurement tools. The authors recognize that a broader agreement on the concept of HAP and on the tools for its measurement is necessary to have wider utility and to facilitate comparisons of healthy ageing across diverse lifestyle-based intervention study designs and studied populations (see Table 1).

Table 1: Tools for measuring select domains and sub-domains of healthy ageing

\begin{tabular}{|c|c|c|}
\hline Domain & Sub-domain & Measures of healthy ageing phenotype \\
\hline \multirow{4}{*}{$\begin{array}{l}\text { 1. Physiological } \\
\text { and metabolic } \\
\text { health }\end{array}$} & 1.1 Cardiovascular function & Blood pressure; blood lipids \\
\hline & 1.2 Lung function & Forced expiratory volume; blood glucose \\
\hline & 1.3 Glucose metabolism & Glycated haemoglobin; waist circumference \\
\hline & 1.4 Body composition & Waist to hip ratio; body mass index (BMI) \\
\hline \multirow{5}{*}{$\begin{array}{l}\text { 2. Physical } \\
\text { capabilities }\end{array}$} & 2.1 Strength & Handgrip strength \\
\hline & 2.2 Locomotion & Gait speed \\
\hline & 2.3 Endurance & Walk endurance test \\
\hline & 2.4 Dexterity & Pegboard dexterity test \\
\hline & 2.5 Balance & Standing balance test \\
\hline \multirow{3}{*}{$\begin{array}{l}\text { 3. Cognitive } \\
\text { functions }\end{array}$} & 3.1 Processing speed & Speed recreation time; symbol digit modalities test \\
\hline & 3.2 Episodic memory & $\begin{array}{l}\text { Story recall; world list recall; paired associate } \\
\text { learning }\end{array}$ \\
\hline & 3.3 Executive function & Stroop; trail making tests A\&B \\
\hline \multirow{5}{*}{$\begin{array}{l}\text { 4. Psychological } \\
\text { well-being }\end{array}$} & 4.1 Positive and negative affect & Positive and negative affect schedule \\
\hline & 4.2 Life satisfaction & Satisfaction with life scale \\
\hline & 4.3 Quality of life & $\begin{array}{l}\text { Control, autonomy, pleasure and self-realization, } \\
\text { quality of life scale; WHO quality of life-BREF }\end{array}$ \\
\hline & 4.4 Mental health & $\begin{array}{l}\text { Center for epidemiological studies depression scale; } \\
\text { Warwick-Edinburgh mental well-being scale }\end{array}$ \\
\hline & 4.5 Resilience & Psychological resilience scale \\
\hline \multirow{4}{*}{$\begin{array}{l}\text { 5. Social well- } \\
\text { being }\end{array}$} & 5.1 Social network & $\begin{array}{l}\text { Lubben social network scale; NIH toolbox: } \\
\text { friendship; PROMIS: companionship }\end{array}$ \\
\hline & 5.2 Social functioning & $\begin{array}{l}\text { Social isolation; PROMIS: satisfaction with social } \\
\text { roles and activities; revised UCLA loneliness scale }\end{array}$ \\
\hline & $\begin{array}{l}\text { 5.3 Perceived emotional/social } \\
\text { support }\end{array}$ & $\begin{array}{l}\text { Social support behaviors scale; NIH toolbox: } \\
\text { emotional support; instrumental support; loneliness; } \\
\text { perceived rejection scale }\end{array}$ \\
\hline & 5.4 Sense of purpose & $\begin{array}{l}\text { NIH toolbox: psychological well-being; meaning } \\
\text { and purpose }\end{array}$ \\
\hline
\end{tabular}

Source: Adapted from Lara et al. (2013: Table 1). 
A second approach for measuring or predicting healthy ageing is discussed by Vanhooren et al. (2009) who use N-glycan profiles as measurement tools. Protein glycosylation is the most common form of co-translational modification of proteins. It increases the diversity of the functions of proteins encoded in the genome. The authors show that two N-glycan structures (NGA2F and NA2F) present in human blood glycoproteins change with ageing, and that one triantennary glycan (NA3Fb) is correlated with tumor stage in hepatocellular carcinoma patients. Therefore, an examination of alterations in the serumglycan fingerprint by using the suggested platform could be a suitable tool for monitoring the healthiness of ageing and for assessing the effectiveness of ageing interventions. It could also be useful for detecting and following up on health conditions and monitoring the effects of treatment.

A third approach for measuring healthy human ageing is obtained from the integrated European project Genetics of Healthy Ageing (GEHA). The aim of the project is identifying genes involved in healthy ageing and longevity. According to Shytthe et al. (2011) in a first step, the project recruited pairs of siblings and a control group for each sibling pair from 11 European countries. A biological sample was collected from each participant and information from basic physical and cognitive measures and from health, lifestyle and family composition were obtained. A large number of nonagenarian siblings aged 90 years or more were also identified and included in the project. In addition, corresponding younger control persons aged 50-75 years were recruited. A total of 2,249 trios were used for genetic analyses. Mortality follow-up improved the possibility of identifying families with the most extreme longevity phenotypes. Shytthe et al. (2011) view the GEHA project as representing a unique source in a search for genes related to healthy ageing and longevity.

\section{Ageing Conditions in Select Countries}

Population aged 60+, 65+ and 80+ years, dependency ratios and old-age support for the world divided into more, less and least developed country groups and further divided into different continents/regions (Africa, Asia, Europe, Latin America, North America and Oceania) was decomposed into males and females and their shares in the total sub-population groups (Table 2). Table 2 shows large variations among country groups by level of development and regions of the world considering ageing and dependency patterns.

\section{Insert Table 2 about here}

This section presents healthy ageing conditions in Europe, USA, India and China. The aim is to identify policies and assess their implementation and outcomes to gain experience in formulating appropriate policies in China to address the challenges of an ageing population.

\subsection{Ageing in Europe and USA}

Health refers to physical, mental and social well-being. Healthy ageing is developing and maintaining optimal health and functions among the elderly in a society. This can be achieved when communities actively promote health and well-being. Thus, an active public ageing policy aims to extend healthy life expectancy and quality of life for citizens as they age. Maintaining autonomy and independence for older people is a key goal in the policy 
framework for practices of active ageing in Europe. Europe is the most resource rich region with an ageing problem in the world that has a well-developed welfare system with large investments in elderly care and quality of life.

The need for healthy ageing is a challenge for all nations. It is predicted that by 2025 about one-third of Europe's population will be aged 60 years and above. In addition, there will be a rapid increase in the number of people above 80 years with greater health service needs. This will have an enormous impact on European societies as health is considered an important determinant of economic growth. Investing in healthy ageing contributes to labor supply and decreasing absenteeism and the likelihood of costly early retirement. Agren and Berensson's (2006) study has a holistic approach and brings together information from healthy ageing literature on health determinants influenced by factors related to individuals, a society and its policies. It presents examples of good policy practices, strategies for healthy ageing and recommendations.

The European Innovation Partnership (EIP) considers active and healthy ageing (AHA) as the process of optimizing opportunities for health to increase life expectancy, healthy life years and quality of life for people as they age. Bousquest et al. (2014) aim to tackle societal challenges through research and innovation. The first launched AHA pursues enabling EU citizens to have healthy ageing, improving social and healthcare systems and boosting and improving the health markets function. The strategic plan that they present defines three priority areas of work involving six specific actions.

A study related to EU by Blain et al. (2014) investigates fighting chronic diseases for active and healthy ageing as part of EIP-AHA at the regional level. It covers different action plans against falls. Falls are the most common and frequent home accidents representing a common and major cause of burden and death among the elderly; they are also considered a social challenge. Through public-private-patient organization partnerships, education, training and raised awareness it aims to change attitudes towards falls and improve access to information on preventing falls to reduce fall-related hospitalization.

Crimmins and Saito (2001) examine healthy life expectancy by gender and education for white and African Americans in the US. They find large racial and educational differences in life expectancy, healthy life expectancy and morbidity by gender. In response to finding long-lasting cost-effective interventions for the high and growing global prevalence of disabling or chronic brain disorders such as Alzheimer's disease, USA and Israeli scientists are engaged in prevention research partnership (see Khachaturian et al., 2010). Their aim is to establish a longitudinal database to investigate cost-effective means to avoid the pending public health catastrophe posed by neurodegenerative diseases. It is expected that research outcomes will help solve dual public health problems of early detections and developing interventions to delay or prevent diseases.

\subsection{Ageing in China and India}

Developing countries experience demographic changes in the form of lowered fertility and an increase in longevity leading to altered population age structures. China has more elderly people than any other country. According to the 2010 census in China the number of people 
aged 65 years and older was 119 million, that is, 8.9 per cent of a population that is ageing fast and is expected to double in half the time that it will take in Europe. By 2050, China's ageing population will match or exceed that of many of today's developed countries. Ageing in China has three distinctive features: (i) Chinese people by tradition rely on their families for old-age support, (ii) China's population has seen a large decrease in its proportion of children as a result of the one-child policy, and (iii) China is undergoing rapid urbanization characterized by massive migration of younger workers from rural regions (Zhao et al., 2014).

The ageing population in China is unique and accelerating and is likely to reach its peak by the middle of the $21^{\text {st }}$ century. Dong and Ding (2009) find the type of products and service scales and their qualities lagging far behind the needs of the elderly. They attempt to identify ways to address the ageing population's needs. They suggest improving geriatric and gerontology education and supporting elderly institutions and elderly care for meeting increased needs and consumption demands. They consider the methods used by other countries as a reference and adapt it to local conditions in China. They suggest changes in traditional elderly care and concepts of death by introducing hospice care. Hospice care is designed to give supportive care to people in the final phase of a terminal illness.

The health of the older population determines its needs for care. Smith et al. (2014) reviewed the positive and negative forces for dynamics of healthy ageing in China. The first positive force was associated with economic development and growth in technology and education over time. A second positive force was attributed to increasing detection and treatment of diseases and reforms that promote the availability of health insurance and health services. The negative forces centered on disturbing trends in personal health behaviors such as growing rates of smoking, obesity and pollution. Other changes related to a changed child policy, rise in fertility rates and rise in continued migration leaving growing numbers of elderly parents geographically separated from their caretaker children. Public health campaigns and a policy that allows elderly people to migrate to their children are suggested to meet the challenges. In 2011-12 proximity of the elderly to their nearest children showed that 37.8 per cent lived with their children, 37.4 per cent had their closest children in the same neighborhood, 15.4 per cent had their closest children in the same county/city, 6.1 per cent did not have their closest children in the same county/city and 3.3 per cent had no living children.

Mohanty (2014) provides comments on Smith et al. (2014) suggesting a number of policy interventions to face healthy ageing in China. One policy instrument is raising the retirement age to improve financial security and sustained economic growth. According to Mohanty, in 2001-11 the growth rate (3.1 per cent) of the elderly in India was twice that of the overall population growth rate. The positive and negative forces of gender disparities, education, longevity, smoking and obesity and health insurance, mentioned in Smith et al. (2014) were observed in India as well. A low retirement age, lower health insurance coverage, inadequate provision of medical care and high patient contributions were among the challenges in India. The Journal of the Economics of Ageing (Bloom and Eggleston, 2014) published a special issue focusing on the economic aspects of an ageing population in the world's two 
population superpowers - China and India. The aim was to fill the gap in literature related to possible economic consequences of demographic trajectories of their population ageing.

In another study, Wang and Chen (2014) discuss that population ageing challenges healthcare in China. According to the China Research Center of Ageing, the elderly population reached 202 million in 2011. More than 100 million had non-communicable diseases, 37 million had diabetes and about 23 million were older than 80 years leading to pressure on healthcare services and widespread social concerns. The authors point to the unfairness and disparities in the health insurance system and insufficient resources available for elderly care leading to a suboptimum chain of services. They recommend accelerating the development of community-based primary healthcare for the elderly, improving basic knowledge about health and investing in health education and promoting health behavior.

China's population and its composition for 1950-2014 by gender and residence are reported in Table 3. The population more than doubled from 552 million to 1,364 billion during this period. Male and female share of the population was around 51.5 and 48.5 per cent respectively. The urban share of the population increased from 11.18 to 54.90 per cent, while the rural share declined from 88.82 to 45.10 per cent.

Table 3: China's population and its composition by gender and residence (1950-2014) (in 10,000)

\begin{tabular}{|c|c|c|c|c|c|c|c|c|c|c|}
\hline & Total & \multicolumn{2}{|c|}{ Male } & \multicolumn{2}{|c|}{ Female } & $\mathrm{M} / \mathrm{F}$ & \multicolumn{2}{|c|}{ Urban } & \multicolumn{2}{|c|}{ Rural } \\
\hline Year & $\begin{array}{l}\text { Populati } \\
\text { on }\end{array}$ & $\begin{array}{l}\text { Popula } \\
\text { tion }\end{array}$ & $\%$ & $\begin{array}{l}\text { Popula } \\
\text { tion }\end{array}$ & $\%$ & $\begin{array}{c}\text { Sex } \\
\text { ratio }\end{array}$ & $\begin{array}{c}\text { Popula } \\
\text { tion }\end{array}$ & $\%$ & $\begin{array}{l}\text { Popula } \\
\text { tion }\end{array}$ & $\%$ \\
\hline 1950 & 55,196 & 28,669 & 51.94 & 26,527 & 48.06 & 1.081 & 6,169 & 11.18 & 49,027 & 88.82 \\
\hline 1955 & 61,465 & 31,809 & 51.75 & 29,656 & 48.25 & 1.073 & 8,285 & 13.48 & 53,180 & 86.52 \\
\hline 1960 & 66,207 & 34,283 & 51.78 & 31,924 & 48.22 & 1.074 & 13,073 & 19.75 & 53,134 & 80.25 \\
\hline 1965 & 72,538 & 37,128 & 51.18 & 35,410 & 48.82 & 1.049 & 13,045 & 17.98 & 59,493 & 82.02 \\
\hline 1970 & 82,992 & 42,686 & 51.43 & 40,306 & 48.57 & 1.059 & 14,424 & 17.38 & 68,568 & 82.62 \\
\hline 1975 & 92,420 & 47,564 & 51.47 & 44,856 & 48.53 & 1.060 & 16,030 & 17.34 & 76,390 & 82.66 \\
\hline 1980 & 98,705 & 50,785 & 51.45 & 47,920 & 48.55 & 1.060 & 19,140 & 19.39 & 79,565 & 80.61 \\
\hline 1985 & 105,851 & 54,725 & 51.70 & 51,126 & 48.30 & 1.070 & 25,094 & 23.71 & 80,757 & 76.29 \\
\hline 1990 & 114,333 & 58,904 & 51.52 & 55,429 & 48.48 & 1.063 & 30,195 & 26.41 & 84,138 & 73.59 \\
\hline 1995 & 121,121 & 61,808 & 51.03 & 59,313 & 48.97 & 1.042 & 35,174 & 29.04 & 85,947 & 70.96 \\
\hline 2000 & 126,743 & 65,437 & 51.63 & 61,306 & 48.37 & 1.067 & 45,906 & 36.22 & 80,837 & 63.78 \\
\hline 2001 & 127,627 & 65,672 & 51.46 & 61,955 & 48.54 & 1.060 & 48,064 & 37.66 & 79,563 & 62.34 \\
\hline 2002 & 128,453 & 66,115 & 51.47 & 62,338 & 48.53 & 1.061 & 50,212 & 39.09 & 78,241 & 60.91 \\
\hline 2003 & 129,227 & 66,556 & 51.50 & 62,671 & 48.50 & 1.062 & 52,376 & 40.53 & 76,851 & 59.47 \\
\hline 2004 & 129,988 & 66,976 & 51.52 & 63,012 & 48.48 & 1.063 & 54,283 & 41.76 & 75,705 & 58.24 \\
\hline 2005 & 130,756 & 67,375 & 51.53 & 63,381 & 48.47 & 1.063 & 56,212 & 42.99 & 74,544 & 57.01 \\
\hline 2006 & 131,448 & 67,728 & 51.52 & 63,720 & 48.48 & 1.063 & 58,288 & 44.34 & 73,160 & 55.66 \\
\hline 2007 & 132,129 & 68,048 & 51.50 & 64,081 & 48.50 & 1.062 & 60,633 & 45.89 & 71,496 & 54.11 \\
\hline 2008 & 132,802 & 68,357 & 51.47 & 64,445 & 48.53 & 1.061 & 62,403 & 46.99 & 70,399 & 53.01 \\
\hline 2009 & 133,450 & 68,647 & 51.44 & 64,803 & 48.56 & 1.059 & 64,512 & 48.34 & 68,938 & 51.66 \\
\hline 2010 & 134,091 & 68,748 & 51.27 & 65,343 & 48.73 & 1.052 & 66,978 & 49.95 & 67,113 & 50.05 \\
\hline 2011 & 134,735 & 69,068 & 51.26 & 65,667 & 48.74 & 1.052 & 69,079 & 51.27 & 65,656 & 48.73 \\
\hline 2012 & 135,404 & 69,395 & 51.25 & 66,009 & 48.75 & 1.051 & 71,182 & 52.57 & 64,222 & 47.43 \\
\hline 2013 & 136,072 & 69,728 & 51.24 & 66,344 & 48.76 & 1.051 & 73,111 & 53.73 & 62,961 & 46.27 \\
\hline 2014 & 136,430 & 70,080 & 51.30 & 66,700 & 48.70 & 1.051 & 74,920 & 54.90 & 61,870 & 45.10 \\
\hline $2014 / 1950$ & 2.472 & 2.444 & 0.988 & 2.514 & 1.013 & 0.972 & 12.145 & 4.911 & 1.262 & 0.508 \\
\hline
\end{tabular}

Source: China Statistical Yearbook (2014). 


\section{The Economics and Policies of Healthy Ageing}

Economics helps determine resource requirements for alternative policies to address healthy ageing. It can help identify different alternative care systems and their associated costs and benefits. Various methods are used to estimate program effects and for selecting the most cost effective care methods. The focus is increasingly on issues of urban migration and investments in infrastructure, health, education and elderly care.

\subsection{The economics of healthy ageing}

Literature on ageing has developed rapidly. A selected list of studies focus on population ageing challenges for healthcare (Dong and Ding, 2009), the role of globalizing local knowledge systems for diets and healthy ageing (Heinrich and Prieto, 2008), healthy ageing and home in Europe (Sixsmith et al., 2014), the ageing of the Chinese population and the cost of healthcare (Hou and Li, 2011), the role of urban design and healthy ageing (Black and Street, 2014), factors of successful ageing (Dahany et al., 2014), ageing, longevity and the health nexus (Rasmussen et al., 2011), healthy ageing in China (Mohanty, 2014; Smith et al., 2014), health status of the elderly (Chao et al., 2013), measuring healthy ageing (Lara et al., 2013) and others.

Table 4: Age composition and dependency ratio of population in China (1990-2014) (in 10,000)

\begin{tabular}{|c|c|c|c|c|c|c|c|c|c|c|}
\hline \multirow{3}{*}{ Year } & & \multicolumn{6}{|c|}{ Age groups } & \multicolumn{3}{|c|}{ Dependency ratio } \\
\hline & \multirow{2}{*}{$\begin{array}{c}\text { Total } \\
\begin{array}{c}\text { Populati } \\
\text { on }\end{array}\end{array}$} & \multicolumn{2}{|c|}{ Aged 0-14 } & \multicolumn{2}{|c|}{ Aged 15-64 } & \multicolumn{2}{|c|}{ Aged 65+ } & \multirow{2}{*}{$\begin{array}{c}\text { Child } \\
\text { ren }\end{array}$} & \multirow{2}{*}{$\begin{array}{c}\text { Elderly } \\
\% \\
(2)\end{array}$} & \multirow{2}{*}{$\begin{array}{c}\text { Gross } \\
\% \\
(1+2)\end{array}$} \\
\hline & & $\begin{array}{c}\text { Popula } \\
\text { tion }\end{array}$ & $\%$ & $\begin{array}{l}\text { Populati } \\
\text { on }\end{array}$ & $\%$ & $\begin{array}{c}\text { Popula } \\
\text { tion }\end{array}$ & $\%$ & & & \\
\hline 1990 & 114,333 & 31,659 & 27.7 & 76,306 & 66.7 & 6,368 & 5.6 & 41.5 & 8.3 & 49.8 \\
\hline 1995 & 121,121 & 32,218 & 26.6 & 81,393 & 67.2 & 7,510 & 6.2 & 39.6 & 9.2 & 48.8 \\
\hline 2000 & 126,743 & 29,012 & 22.9 & 88,910 & 70.1 & 8,821 & 7.0 & 32.6 & 9.9 & 42.6 \\
\hline 2001 & 127,627 & 28,716 & 22.5 & 89,849 & 70.4 & 9,062 & 7.1 & 32.0 & 10.1 & 42.0 \\
\hline 2002 & 128,453 & 28,774 & 22.4 & 90,302 & 70.3 & 9,377 & 7.3 & 31.9 & 10.4 & 42.2 \\
\hline 2003 & 129,227 & 28,559 & 22.1 & 90,976 & 70.4 & 9,692 & 7.5 & 31.4 & 10.7 & 42.0 \\
\hline 2004 & 129,988 & 27,947 & 21.5 & 92,184 & 70.9 & 9,857 & 7.6 & 30.3 & 10.7 & 41.0 \\
\hline 2005 & 130,756 & 26,504 & 20.3 & 94,197 & 72.0 & 10,055 & 7.7 & 28.1 & 10.7 & 38.8 \\
\hline 2006 & 131,448 & 25,961 & 19.8 & 95,068 & 72.3 & 10,419 & 7.9 & 27.3 & 11.0 & 38.3 \\
\hline 2007 & 132,129 & 25,660 & 19.4 & 95,833 & 72.5 & 10,636 & 8.1 & 26.8 & 11.1 & 37.9 \\
\hline 2008 & 132,802 & 25,166 & 19.0 & 96,680 & 72.7 & 10,956 & 8.3 & 26.0 & 11.3 & 37.4 \\
\hline 2009 & 133,450 & 24,659 & 18.5 & 97,484 & 73.0 & 11,307 & 8.5 & 25.3 & 11.6 & 36.9 \\
\hline 2010 & 134,091 & 22,259 & 16.6 & 99,938 & 74.5 & 11,894 & 8.9 & 22.3 & 11.9 & 34.2 \\
\hline 2011 & 134,735 & 22,164 & 16.5 & 100,283 & 74.4 & 12,288 & 9.1 & 22.1 & 12.3 & 34.4 \\
\hline 2012 & 135,404 & 22,287 & 16.5 & 100,403 & 74.1 & 12,714 & 9.4 & 22.2 & 12.7 & 34.9 \\
\hline 2013 & 136,072 & 22,329 & 16.4 & 100,582 & 73.9 & 13,161 & 9.7 & 22.2 & 13.1 & 35.3 \\
\hline 2014 & 136,430 & 22,560 & 16.4 & 100,470 & 73.3 & 13,760 & 10.1 & 22.5 & 13.7 & 36.2 \\
\hline $2014 / 1990$ & 1.193 & 0.713 & 0.592 & 1.317 & 1.099 & 2.608 & 1.804 & 0.542 & 1.651 & 0.727 \\
\hline
\end{tabular}

Source: China Statistical Yearbook (2014).

With reference to population projections for $2050 \mathrm{Hou}$ and Li (2011) suggest that there will be about 115 million elderly citizens over 80 years of age requiring serious planning to cope 
with the demand in China. The authors provide quantitative measures of the elderly dependency ratio and the cost of medical insurance. The medical insurance premium varies greatly by costal/inland, rural/urban and gender dimensions. Healthcare services have traditionally been biased towards the urban population. Using the Taiwanese experience, Hou and Li propose incentive schemes to manage and reduce the costs of healthcare. They show a shifting population pyramid for China in 1990, in 2010 and for the future in 2050. They recommend balanced development and significant investments in health to ease the burden of an ageing population. Table 4 shows that the share of children in the $0-14$ years age group declined from 27.7 per cent in 1990 to 16.4 per cent in 2014, while the share of adults (15-64 years) and that of the elderly (65+ years) increased from 61.5 and 4.9 per cent to 73.3 and 10.1 per cent respectively. The gross and children dependency ratios declined, while that for the elderly increased from 8.3 to 13.7 per cent.

Qiu (2007) and Wang and Chen (2014) state that China's ageing population is facing a ticking time bomb. China has 6 million patients with dementia and, with a rapidly ageing population, it will have 1 million such new cases every year. It is predicted that by 2040 China will have as many people with dementia as there are in the rest of the world. Dong and Ding (2009) look at ageing in China both as a challenge and also as an opportunity. It is crucial for the government to plan policies and allocate health and welfare resources for the future. They try and identify ways of addressing China's ageing population needs. Increased needs of the elderly can be meet through improving geriatric care, education, supporting elderly institutions and elderly healthcare and changing the traditional concept of death.

\subsection{Urban healthy ageing}

China has seen the largest human migration in history after the open door policy of the 1970s. Migration has strong implications for public health services. Gong et al. (2012) use provincial data to give evidence of a rapid trend in rural-to-urban migration. Growing sizes of cities and urban population together with insufficient urban infrastructure, growing environmental problems and hazardous living environments as well as disease burden are major urban public health challenges. To address these health challenges, Gong et al. (2012) suggest innovative health policies which focus on the needs of the migrants. They also suggest research to close knowledge gaps in urban population exposures. The authors list a number of economic, social and environmental push and pull factors driving migration in China. They suggest policies to mitigate its adverse effects and innovative health policies that sustainably address the health needs of generations.

Health status and associated factors such as community dwellings for the elderly in Nanjing in China are evaluated by Chao et al. (2013). An elderly health assessment index system rating different groups suggests a non-optimal general health status. The dimensions of the index system include body function, self-care ability, emotional personality, and memory functions. Body function, self-care ability and physical health have declined with age faster for males as compared to females. Education, living conditions and marital status have positively influenced the health status and health needs of the elderly. The findings demonstrate that emotional and social support are more important than financial support for 
promoting mental health of the elderly. They provide a basis for developing health management with a focus on healthy ageing of the elderly in China.

Residential care is increasingly becoming an alternative option for many of the elderly in Beijing. Research by Cheng et al. (2011) sheds light on the well-being of elderly residents in residential care facilities and how the environment affects their everyday activities and health. Seen from a multi-perspective of health geography they try and understand the relationship between ageing, health and the living environment. The results show that the general well-being of the residents is satisfactory but some individuals feel isolated and depressed after their relocation. Physical and social environment, individual characteristics and family support influence their well-being. The study sheds light on future research on geographical and socio-cultural meanings of elderly care in Beijing.

Urbanization effects human health through demographic shifts. It also challenges urban sustainability involving balancing aspects such as culture, socioeconomic, technical, environmental and ecological factors. Li et al. (2012) reviewed research on this relationship in China, Southeast Asia and East Asia with large populations and rapid urbanization. Tables 5 and 6 show that the urban population in China increased by 63.2 per cent between 2000 and 2014. The corresponding increase in the share of the elderly in the urban population was 56.8 per cent. Urbanization offers both opportunities for improvements and also leads to problems with public safety, public health and social equity. China is a major contributor to the worldwide infectious disease burden. Japan provides many good examples of how to achieve urban sustainability by a better understanding of the urbanization and human health relationship.

Table 5: Selected data on population in China (2000-2013)

\begin{tabular}{|c|c|c|c|c|c|c|c|c|c|}
\hline \multirow[b]{2}{*}{ Year } & \multicolumn{3}{|c|}{ Population rates, \% } & \multicolumn{2}{|c|}{ Crude rate, \% } & \multicolumn{2}{|c|}{$\begin{array}{c}\text { Life Expectancy, } \\
\text { years }\end{array}$} & \multicolumn{2}{|c|}{ Mortality } \\
\hline & $\begin{array}{l}\text { Birth } \\
\text { (1) }\end{array}$ & $\begin{array}{l}\text { Death } \\
(2)\end{array}$ & $\begin{array}{c}\text { Natural } \\
\text { Growth } \\
(1-2)\end{array}$ & $\begin{array}{l}\text { Marria } \\
\text { ge }\end{array}$ & $\begin{array}{l}\text { Divorc } \\
\mathrm{e}\end{array}$ & $\begin{array}{c}\text { Life } \\
\text { expecta } \\
\text { ncy } \\
\text { Male }\end{array}$ & $\begin{array}{c}\text { Life } \\
\text { expecta } \\
\text { ncy } \\
\text { Female }\end{array}$ & $\begin{array}{c}\text { Under } \\
5 / 1000 \\
\text { birth }\end{array}$ & $\begin{array}{c}\text { Materna } \\
1 / 100,00 \\
0 \\
\text { persons }\end{array}$ \\
\hline 2000 & 14.03 & 6.45 & 7.58 & 6.7 & 1.0 & 73.8 & 79.6 & 39.7 & 53.0 \\
\hline 2005 & 12.40 & 6.51 & 5.89 & 6.3 & 1.4 & 74.5 & 80.8 & 22.5 & 47.4 \\
\hline 2006 & 12.09 & 6.81 & 5.28 & 7.2 & 1.5 & 74.9 & 81.4 & 20.6 & 41.1 \\
\hline 2007 & 12.10 & 6.93 & 5.17 & 7.5 & 1.6 & 75.5 & 81.7 & 18.1 & 36.6 \\
\hline 2008 & 12.14 & 7.06 & 5.08 & 8.3 & 1.7 & 75.6 & 81.9 & 18.5 & 34.2 \\
\hline 2009 & 11.95 & 7.08 & 4.87 & 9.1 & 1.9 & 76.0 & 82.3 & 17.2 & 31.9 \\
\hline 2010 & 11.90 & 7.11 & 4.79 & 9.3 & 2.0 & 76.2 & 82.6 & 16.4 & 30.0 \\
\hline 2011 & 11.93 & 7.14 & 4.79 & 9.7 & 2.1 & 76.0 & 82.6 & 15.6 & 26.1 \\
\hline 2012 & 12.10 & 7.15 & 4.95 & 9.8 & 2.3 & 76.2 & 83.0 & 13.2 & 24.5 \\
\hline 2013 & 12.08 & 7.16 & 4.92 & 9.9 & 2.6 &.. & .. & 12.0 & 23.2 \\
\hline 2013/2000a & 0.861 & 1.110 & 0.649 & 1.478 & 2.600 & 1.032 & 1.043 & 0.302 & 0.438 \\
\hline
\end{tabular}

Sources: China Statistical Yearbook (2014); BRICS joint statistical publication (2015).

Note: 'a' indicates ratio of 2013 or 2012 to 2000.

The issue of healthy ageing at home in five European countries is studied by Sixsmith et al. (2014). They examine the relationship between home and healthy ageing through the ways in which old people perceive healthy ageing by living alone at home within urban settings. 
The data analysis identifies five ways in which they construct elderly healthy ageing with practice and policy implications: home and keeping active, managing lifestyles, health and illnesses, balancing social life and balancing material and financial circumstances. The research suggests a number of measures for enhancing the notion of healthy ageing and creating meaningful spaces. In sum, the home environment is found to play a significant role in developing and supporting personal strategies for healthy ageing.

Table 6: Key economic, labor market and population characteristics in China (1990-2013)

\begin{tabular}{|l|r|r|r|r|r|r|r|r|}
\hline & \multicolumn{3}{|c|}{ GDP per capita } & \multicolumn{2}{c|}{ Average wage } & \multicolumn{3}{c|}{ Employed at: } \\
\hline Year & $\begin{array}{c}\text { Current } \\
\text { Yuan } \\
\text { constant } \\
\text { price }\end{array}$ & $\begin{array}{c}\text { Growth } \\
1978= \\
100\end{array}$ & $\begin{array}{c}\text { health } \\
\text { and } \\
\text { social } \\
\text { services } \\
\text { social } \\
\text { security } \\
\text { and } \\
\text { social } \\
\text { org. }\end{array}$ & $\begin{array}{c}\text { Total in } \\
10,000\end{array}$ & $\begin{array}{c}\text { health } \\
\text { and } \\
\text { social } \\
\text { services }\end{array}$ & $\begin{array}{c}\text { public } \\
\text { manageme } \\
\text { nt, social } \\
\text { security } \\
\text { and org. }\end{array}$ \\
\hline 2003 & 10,542 & 109.3 & 733.1 & 16,185 & 15,355 & 73,736 & 127.8 & $1,171.0$ \\
\hline 2004 & 12,336 & 109.4 & 802.2 & 18,386 & 17,372 & 74,264 & 123.4 & $1,199.0$ \\
\hline 2005 & 14,185 & 110.7 & 887.7 & 20,808 & 20,234 & 74,647 & 122.5 & $1,240.8$ \\
\hline 2006 & 16,500 & 112.0 & 994.7 & 23,590 & 22,546 & 74,978 & 122.4 & $1,265.6$ \\
\hline 2007 & 20,169 & 113.6 & $1,129.6$ & 27,892 & 27,731 & 75,321 & 125.0 & $1,291.2$ \\
\hline 2008 & 23,708 & 109.1 & $1,232.1$ & 32,185 & 32,296 & 75,564 & 126.0 & $1,335.0$ \\
\hline 2009 & 25,608 & 108.7 & $1,339.0$ & 35,662 & 35,326 & 75,828 & 129.5 & $1,394.3$ \\
\hline 2010 & 30,015 & 109.9 & $1,471.7$ & 40,232 & 38,242 & 76,105 & 131.4 & $1,428.5$ \\
\hline 2011 & 35,198 & 108.8 & $1,600.9$ & 46,206 & 42,062 & 76,420 & 135.0 & $1,467.6$ \\
\hline 2012 & 38,459 & 107.1 & $1,715.1$ & 52,564 & 46,074 & 76,704 & 137.7 & $1,541.5$ \\
\hline 2013 & 41,908 & 107.1 & $1,837.5$ & 57,979 & 49,259 & 76,977 & 147.0 & $1,567.0$ \\
\hline $2013 / 2003$ & 3.975 & 0.980 & 2.506 & 3.582 & 3.208 & 1.044 & 1.150 & 1.338 \\
\hline
\end{tabular}

Source: China Statistical Yearbook (2014).

Black and Street (2014) explore the role of urban design in cycling behaviors and healthy ageing. They suggest that a good urban design provide an inclusive journey environment for elderly cyclists. A better understanding of elderly cyclists' experiences and perceptions of the urban environment influences their mobility and physical activities. In facing ageing and health challenges some European metropolitans combine urban design, policy and inclusive infrastructure initiatives. Black and Street's (2014) research provides an understanding of the principles of the quality of urban design and features of the built environment that affect participation in cycling with the aim of contributing towards a healthy ageing agenda.

\section{Investments in Healthy Ageing}

This section provides a review of literature on investments in healthy ageing that can have positive effects on healthy ageing outcomes aimed at reducing social inequalities and meeting the needs and costs of elderly care. The types of investments are related to changed attitudes towards a multidimensional view of well-being; an assessment of the effects of therapy on the quality of life; investments in child heath to foster healthy ageing and promoting dietary patterns; exercise habits with health linkages; the use of an integrative 
approach to learning and community-based care; and an emphasis on the determinants of successful ageing.

\subsection{Investments in well-being of specific groups}

In parallel with increased productivity of labor and the number of elderly, the Chinese central and provincial governments have made significant investments in healthcare infrastructure. Improved knowledge and technology development have influenced the rates of birth, death and natural population growth rates. The GDP per capita grew 18.4 times between 1978 and 2013. This rapid growth has enabled investments in health, social services and social organizations (see Table 6). It has also led to increased disposable incomes leading to high consumption of utilities, housing, education, transportation, communication, health, pension and other welfare enhancing activities as well as negative environmental externalities (see Table 7).

\section{Insert Table 7 about here}

Unlike the Marmot Review's (2010) argument that societies should focus on reducing health inequalities by removing the unfair socioeconomic gradient in health and reducing social inequalities, Canning and Bowser (2010) argue that a better goal is improving health, income and socioeconomic outcomes for the most disadvantaged in society through direct health interventions particularly in early childhood. In contrast to economists with a simple focus on income or consumption per capita as a measure of well-being, researchers also suggest a multidimensional view of well-being as being more plausible (Bersisa and Heshmati, 2016; Maasoumi and $\mathrm{Xu}, 2015)$. Dimensions of well-being should ideally include consumption, wealth, health, education, housing, personal activity, political voice and governance, social connectedness, environmental conditions and personal and economic securities.

Kim (2013) studies the effects of art therapy on healthy ageing in older Korean American adults in terms of promoting well-being and a better quality of life. The objective of Kim's study is to quantitatively assess the effects of art therapy using affect, anxiety and self-esteem as instruments for outcomes. The results show positive effects of therapy promoting better health for older individuals in terms of reducing negative emotions, improving self-esteem and decreasing anxiety.

Increased life expectancy has led to increased focus on healthy ageing of the elderly. Addressing the full ageing process including the younger population in ageing research is important. Felix et al. (2014) have developed a conceptual framework for child health which is treated as a dynamic state permitting optimal physical, mental and social functioning. Here an optimal child quality of life is used as the starting point for healthy ageing research. They propose five core dimensions of child health: absence of physical disease; absence of psychiatric disorders; optimal physical, mental and social functioning; good quality of life or well-being; and adequate resilience. This conceptualization of child health and its dimensions can serve as a platform for building a framework for future studies in the area with a broader focus on healthy ageing across the life course. 


\subsection{Healthy ageing and diet}

Research shows that diet and health are strongly linked. There is a tendency towards functionalizing food tailor-made for specific groups in society. Diet is an efficient way of allowing for healthy ageing. In an earlier study Heinrich and Prieto (2008) assessed how diet has evolved in the past century to make inferences about diet in the future. Of particular interest are explanations of changes in dietary habits and their impact on health as well as transitions from local to global and science-based evidence. Besides being healthy the food must also be convenient and easy to prepare. Thus, healthy ageing requires looking at a multitude of aspects of food. Trends at the interface of health and diet are defined according to Sadler (2005) by six keywords related to: glycemic index, healthy heart, well-being, daily dosing, low fat to right fat and functional food. Sadler provides a list of consumer and manufacturer driving factors for each health trend.

A number of dietary patterns are associated with reduced risks for cardiovascular and agerelated diseases. The traditional diet of Okinawa, Mediterranean, the DASH (Dietary Approach to Stop Hypertension) diet and the Portfolio (cholesterol lowering) diet are among such dietary patterns which share characteristics and nutrient content which have gained significant attention from researchers and health and social policy planners. The important shared features of these healthy dietary patterns include high intake of unrefined carbohydrates, moderate protein intake with emphasis on vegetables/legumes, fish and lean meats as sources, a healthy fat profile and daily Jasmine tea and physical activity (Willcox et al., 2014) (also see Table 8). Together they reduce the socioeconomic costs of chronic diseases and promote healthy ageing, longevity and quality of life. Effective public health policies and programs can do much to mitigate risks and help individuals remain healthy as they age.

Table 8: Ten characteristics of the traditional Okinawa diet

\begin{tabular}{|l|l|}
\hline Items & The characteristics \\
\hline 1. & Low caloric intake \\
\hline 2. & High consumption of vegetables (particularly root and green-yellow vegetables) \\
\hline 3. & High consumption of legumes (mostly soybean in origin) \\
\hline 4. & Moderate consumption of fish products (more in coastal areas) \\
\hline 5. & Low consumption of meat products (mostly lean pork) \\
\hline 6. & Low consumption of dairy products \\
\hline 7. & Low fat intake (high mono and polyunsaturated-to-saturated fat ratio; low omega) \\
\hline 8. & Emphasis on low-GI carbohydrates \\
\hline 9. & High fiber intake \\
\hline 10. & Moderate alcohol consumption \\
\hline
\end{tabular}

Source: Adapted from Willcox et al. (2014).

Along similar lines, Zhao et al. (2013) investigate empirical relationships between diet, chronic health outcomes and health information. They disentangle the effects of income on demand for health and the role of information on the health status of consumers by adjusting their lifestyles toward healthier ones. On receiving negative health information individuals are expected to adjust their diet in a healthier direction. Based on Chinese data, the authors present evidence on the effects of hypertension diagnosis on food consumption. The results 
show that changes in food consumption and health outcomes are influenced by individuals' levels of education and income.

Healthy dietary and exercise habits contribute to healthy ageing and quality of increasing life expectancies. Hammar and Ostgren (2013) refer to certain types of diets that can prevent or reduce obesity and the risk of diseases. Exercise and activities suited for individuals can also be tailored to reduce the risk of cardiovascular diseases. Thus age-adjusted modifiable lifestyle factors such as diet and exercise can be strong promoters of healthy ageing, improving well-being and preventing diseases as they play a role in maintaining optimal cognitive, mental and physical health into advanced age.

\subsection{Other factors supporting healthy ageing}

Increased life expectancies and the need to maintain health in the older age are key challenges facing governments across the world. Shneerson et al. (2014) find that health systems based on a biomedical model with focus on core specific conditions are ill-suited for the complex needs of older people. They fail to be person-centered in providing opportunities for integrated working. The authors suggest interpersonal education aimed at training multi-disciplinary healthcare students and members of communities as being more beneficial in engaging with some of these challenges. The shared care and integrative approach to learning can be achieved by getting patients and the public to collaborate in supporting healthy ageing and improving links to social care. It is expected that the new approach will promote a community-based, preventive, integrative, interactive and positive approach to healthy ageing.

Silva and Correia (2014) discuss ways in which the web and telecommunications have brought beneficial changes to people's daily lives. They also point to the fact that advancements in the digital world have also created a digital divide from the perspective of internet access and use. In particular, elderly people have been affected by the divide as they lack relevant skills. New solutions tailored to the needs of the elderly therefore need to be suggested. In order to understand how technology and social networking can enhance elders' lives and promote active ageing, Silva and Correia (2014) discuss the challenges of changing paradigms and adjusting to new trends in emerging technologies. ActiveBrain ${ }^{2}$ is a social online cognitive training platform. It covers brain training, stress sharing and elderly support to maintain elders' interpersonal communications by being socially connected with others.

There is a desire to identify factors associated with successful ageing defined with health related to the quality of life. Dahany et al. (2014) identify such factors which are defined by a score on the general health dimension to investigate the association between successful ageing and socio-demographic, psychological, physical and behavioral factors. The results show that lower weight, regular physical activity and religious beliefs positively influence ageing, while psychological distress, co-morbidities and obesity influence it negatively. Similar results related to psychological, physical and regular physical activity and a balanced

\footnotetext{
${ }^{2}$ http://activebraincenter.com/wp/.
} 
diet as major determinants of successful ageing are found in other studies which serve as elements of policies and programs for promoting healthy ageing.

\section{An Optimal Healthy Ageing Policy in China}

Available statistics on the present demographic structure and forecasts for the future development of the population structure of the elder cohort in China suggest serious economic and social challenges. These challenges can best be met by optimal healthy ageing in society. Major sources of the increased numbers of elderly people are the one-child policy of the 1970s, technological progress, education, health insurance and improved living standards. These have jointly led to not only improved health and subsequent continuous increasing average life expectancies but also deteriorated trends in personal behavior and health attributed to growing rates of obesity, smoking and drinking habits. Other significant changes include pollution, the changed one-child policy, increased fertility, continued ruralto-urban migration, an increased overall dependency ratio and dependency on public health services and care provisions. In the long term these will negatively influence China's labor productivity, economic growth and competitiveness.

The increased productivity of labor has generated resources for investments in education, knowledge and technological progress which have further strengthened their causal relationships. As part of the process, the state has made significant investments in various productive and well-being infrastructures. As a result, changes are observed in birth and death rates and the living conditions of the population. Production and consumption increases, in particular in transport, water and energy resources have negatively influenced the environment. Tables 6 and 7 show that investments in fixed assets, housing and waste treatment, provision of basic pensions, supply of health insurance and health services and social security and organizations have increased which have positively influenced longevity and healthy ageing. They are important means for coping with the challenges of ageing.

Since the health of the older population is a key determinant of its need for resources and care, it is important to consider ageing as an opportunity to search for optimal healthy ageing to meet the economic and social challenges of the aging population. Investments in healthy ageing contribute to general economic and social well-being and reduce pressure on providing services to a rapidly growing ageing population. A number of alternative approaches can be used in an effort to meet the rapidly growing ageing population in China. Both micro and macro data and population statistics are used to quantify the problem, the resources required and the socioeconomic benefits of a healthy ageing policy as also the measures implemented. The current state and identified alternative healthy ageing approaches are now summarized.

\subsection{The current state and conditions}

Persistent increases in average life expectancy regardless of the level of development and location are viewed by Rasmussen et al. (2011) as a phenomenon that will bring social, economic, political and biomedical challenges both for current and future generations. The current multifaceted and interdisciplinary research approaches have aimed at developing 
interventions to enhance the quality of life while increasing its length, and to develop cost efficient methods given the limited available resources allocated to various competing medical, social, economic and other priorities of different age cohorts.

A segment of literature which emphasizes on health inequalities and healthy ageing in the context of a fair society has received significant attention. This has led to a number of inquiries into the state of health inequalities and fairness. The Marmot Review (Marmot et al., 2010) provides a strategic review of health inequalities in England. It can serve as a model to shed light on health inequalities in China and to make policymaking more health inequality reducing. Gains can also be made by using an economist's perspective on health inequalities discussed in Chandra and Vogl (2010) to leap shorter distances between accumulated knowledge and economically implementable policies.

An attempt is also made in literature to employ different approaches to measure healthy ageing using a multidimensional measure with focus on biological ageing and the protection of longevity and genetic healthy ageing dimensions. Lara et al. (2013) found that biological ageing as a complex process can be measured by tools developed by identifying the key features of healthy ageing. Vanhooren et al. (2009) have suggested prediction of healthy ageing by using $\mathrm{N}$-gylcan profiles as a suitable tool for monitoring the healthiness of ageing and for assessing the effectiveness of ageing interventions. Shytthe et al. (2011) describe another approach which focuses on identifying genes related to healthy ageing and longevity. These and other approaches are frequently used in research.

In Europe and the US that are already challenged by ageing, various community programs are being developed to actively improve social and healthcare systems and the market. These are expected to promote health and well-being and prevent or minimize prevalence of various diseases. The aim of the active ageing policy implementable in the Chinese case is extending healthy life expectancies and quality of life as people age while maintaining autonomy and independence for the older people. For instance, action plans against falls which is the most common and frequent home accident and burden and death among the elderly are common preventive actions. Another area of prevention is global efforts to find long-lasting and cost effective interventions for chronic brain disorders such as Alzheimer's disease.

The share of the elderly in China's total population is accelerating fast. The distinct features of the Chinese elderly are the tradition of high reliance on the family for care, a decline in the share of children and rapid rural-to-urban migration leaving the elderly behind. These have made the current level and quality of services fall short of the needs of the elderly. Among the recommendations made are improving geriatric and gerontology education, supporting elderly care institutions and making changes in traditional care for the elderly. Despite many positive development trends, the health of the elderly remains a key determinant in their care needs. As Wang and Chen (2014) have pointed out, the unfairness and disparities in the health insurance system and insufficient resources available for elderly care are factors leading to suboptimum services. Developing community-based primary healthcare and policy interventions are in progress. 


\subsection{Policy recommendations based on existing best practices}

Economic literature on healthy ageing is growing. The focus of this literature is on the cost of healthcare for the ageing; some others have also investigated the benefits of investments in healthy ageing and health status and the factors influencing it. Conditions imply that there is a need to seriously plan to cope with increasing demands for elderly care. In this regard following Hou and Li (2011) providing quantitative measures for the elderly dependency ratio and medical insurance premium for various groups are urgent as this will help find balanced development and investment in health to ease the burden of the ageing population. An increasing number of patients with dementia have been seen as a time ticking bomb by Wang and Chen (2014) which requires that policy planning, policy measures and allocation of health and welfare resources for the future be given priority. Improved geriatrics, education, supporting elderly institutions and elderly healthcare and changing care traditions are among the other measures which need to be adopted to meet the needs of the elderly in China more efficiently.

The largest rural-to-urban migration in China can have strong implications for public safety, public health, healthcare services and social equity. Growing city sizes and urban populations combined with insufficient infrastructure, growing environmental problems, hazardous living environments and disease burden are major new public health challenges. In this regard as suggested by Gong et al. (2012) innovative health policies can help meet growing demand and research resources to close the knowledge gap to sustainably address the health needs of generations. A multidimensional index rating general health status of the elderly by assessing dimensions such as body function, self-care ability, emotional personality and memory function for different groups suggested by Chao et al. (2013) is useful. This index can help assess the influence of the physical and social environment, individual characteristics and family support on elders' physical and sociological well-being.

The relationship between home and healthy ageing within urban settings as examined by Sixsmith et al. (2014) found five efficient ways to perceive healthy ageing: living at home and staying active; managing lifestyles, health and illnesses; balancing social life; and balancing material and financial circumstances. These ways can be adapted to allow the home environment to play a significant role in developing and supporting personal strategies for healthy ageing and for managing elderly healthcare in China. A combination of urban design, policy and infrastructure initiatives should influence mobility and physical activities by the elderly. Such policies are implementable in China.

The Marmot Review (2010) and Canning and Bowser's (2010) argument that societies should focus on reducing health inequalities and improving health, income and socioeconomic outcomes for the most disadvantaged in society through direct health interventions are complementary and implementable in China's context. A multidimensional view of well-being focusing on aspects like consumption, wealth, health, education, personal activity, political voice and governance, social connectedness, environmental conditions and personal and economic insecurities is also desired. As suggested by Felix et al. (2014) child health as a starting point for research in healthy ageing plays a strong preventive role. 
In line with research by Sadler (2005), Heinrich and Pietro (2008) and Hammar and Ostgren (2013) the link between health, diet and physical activities is found to be vital. An adjusted and modifiable diet tailor-made for specific groups and activities to allow for healthy ageing are important. The health-diet linkage should also be accounted for when it comes to discussing changes in habits and other aspects of food which are deriving factors for health trends. Diets are associated with reduced obesity allowing reduced risks of cardiovascular and age-related costly diseases. In this regard the Okinawa, Mediterranean, DASH and Portfolio diets which are dietary patterns that share desirable characteristics and nutrient content to maintain optimal cognitive, mental and physical health into advanced age should be promoted. Investments in education and household incomes can influence optimal changes in food consumption and chronic health outcomes.

Other factors supporting healthy ageing include an integrative approach involving patients and the public for supporting healthy ageing and links to social care. In line with Shneerson et al. (2014) the resulting system should promote community-based, preventive, integrative and a positive approach to healthy ageing. Also in line with Silva and Correia (2014) the web, telecommunications and ActiveBrain which is a social online cognitive platform for brain training, stress sharing and elderly support to maintain their interpersonal communications and social connectedness are attractive measures in an information society. According to Dahany et al. (2014) these measures complement other identified sociodemographic, psychological, physical and behavioral factors with a positive association with successful ageing and a better quality of life.

\section{Summary and Conclusions}

There is an increasing need for having an approach to healthy ageing as an efficient way of addressing the challenges of the rapidly increasing number of elderly in China. The ageing population is referred to as a ticking time bomb. Since health is an important determinant of economic growth and competiveness, investments in health at an early stage will help achieve the objectives of optimal healthy ageing and thereby reduce resources and costs of care while contributing positively to economic and social well-being. This study provided a review of literature on healthy ageing focusing on alternative approaches, policies, practices and resources to ease pressures from an ageing population and their estimated benefits and quantified effects. The review also proposed a blend of policies to form an optimal perspective on healthy ageing in China.

The major reasons for increased numbers of elderly in China are the one-child policy, higher education, technological progress, health insurance, improved material standards and rapid urbanization. These explain continuous increasing life expectancies while deteriorating trends in personal behavior such as smoking, obesity and pollution contribute to the increased need for costly healthcare. None of the former categories can or should be reversed, while the behavioral factors can be influenced through preventive investment measures to reduce resource needs in the long run, at the same time improving general economic and social well-being in society. 
A summary of the present situation in China reveals that health in general should refer to physical, mental and social well-being, while healthy ageing should be defined in a multidimensional manner as developing and maintaining health and functions in elder adults. The proposed measures focus among others on biological ageing, protection of longevity, generic health ageing, prediction of healthy ageing and identifying genes related to healthy ageing and longevity. In recent decades, notable awareness about the ageing problem and development of strategies, policies, organization, resources and practices to cope with ageing pressures have been noticed. There is evidence also of the long term social and economic benefits of such investments.

The current interdisciplinary research's focus is on developing therapeutic interventions with high resource-use priorities to enhance the quality of life and on developing cost effective care methods. While looking at the limited resources for addressing the ageing problem, coping with health inequalities and fairness; reducing the distance between knowledge and policies; developing various integrative community programs; investing in education and public safety; disease prevention; improved geriatrics;, changes in care traditions; extending healthy lives and their quality; and cost effective interventions for chronic brain disorders are among the active measures practiced. The relationship between home and healthy ageing, interpersonal and socially connectedness, health-diet linkages, maintaining optimal cognitive, metal, physical and social relationships in an age of urbanization and information society is an efficient way of looking at healthy ageing.

\section{References}

Agren, G. and K. Berensson (2006), Healthy Ageing: A Challenge for Europe. The Swedish National Institute of Public Health R 2006:29.

Bersisa, M. and A. Heshmati (2016), Multidimensional measure of poverty in Ethiopia: Factor and stochastic dominance analysis, in Almas Heshmati, Poverty and Well-Being in East Africa: A Multi-faceted Economic Approach, Chapter 10, Springer: Singapore.

Blain, H., F. Abecassis, ..., J. Bousquet (2014), Living Lab Falls-MACVIA-LR: The falls prevention initiative of the European Innovation Partnership on Active and Healthy Ageing (EIP on AHA), European Geriatric Medicine 5: 416-425.

Black, P. and E. Street (2014), The Power of Perceptions: Explaining the Role of Urban Design in Cycling Behaviours and Health Ageing, Transportation Research Procedia 4: 68-79.

Bloom, D.E. and K.N. Eggleston (2014), Editorial. The economic implications of population ageing in China and India: Introduction to the special issue, The Journal of the Economics of Ageing 4: 1-7.

Bousquet, J. et al. (2014), Editorial. The European Innovation Partnership on Active and Healthy Ageing: The European geriatric medicine introduces the EIP on AHA column, European Geriatric Medicine 5: 361-362. 
Canning, D. and D. Bowser (2010), Investing in health to improve the well-being of the disadvantaged: Reversing the argument of Fair Society, Healthy Lives (The Marmot Review), Social Science and Medicine 71: 1223-1226.

Chao, J. et al. (2013), Health Status and Associated Factors among the Community-Dwelling Elderly in China, Archives of Gerotology of Geriatrics 56: 199-204.

Chandra, A. and T.S. Vogl (2010), Rising up with shoe leather? A comment on Fair Society, Healthy Lives (The Marmot Review), Social Science and Medicine 71: 1227-1230.

Cheng, Y. et al. (2011), Aging, health and place in residential care facilities in Beijing, China, Social Science and Medicine 72: 365-372.

Crimmins, E.M. and Y. Saito (2001), Trends in healthy life expectancy in the United States, 1970-1990: gender, racial, and educational differences, Social Science and Medicine 52: $1629-1641$.

CSDH (2008), Commission on the Social Determinants of Health. Final report. Closing the gap in a generation: health equity through action on the social determinants of health. Geneva: World Health Organization.

Dahany, M.M. et al. (2014), Factors Associated with Successful Ageing in Persons Aged 65 to 75 Years, European Geriatric Medicine 5: 365-370.

Department of Health (2010), Marmot Review. Fair society, healthy lives: strategic review of health inequalities in England post 2010. London: The Institute of Health Equity.

Dong, B. and Q. Ding (2009), Ageing China: A Challenge or an Opportunity. Special Articles, Journal of the American Medical Directors Association 10(7): 456-458.

Felix, J.F. et al. (2014), Health in children: A conceptual framework for use in healthy ageing research, Maturitas 77: 47-51.

Gong, P. et al. (2012), Urbanisation and health in China, The Lancet 379: 843-852.

Hammar, M. and C.J. Ostgren (2013), Healthy aging and age-adjusted nutrition and physical fitness, Best Practice and Research Clinical Obstetrics and Gynaecology 27: 741-752.

Heinrich, M. and J.M. Prieto (2008), Diet and Healthy Ageing 2100: Will We Globalise Local Knowledge System? Ageing Research Reviews 7: 249-274.

Hou, J.W. and K. Li (2011), The Ageing of the Chinese Population and the Cost of Health Care, The Social Science Journal 48: 514-526.

Khachaturian A.S., et al. (2010), Healthy Ageing and Preclinical Dementia: The United States-Israel Longitudinal Database Project, Alzheimer's and Dementia 6: 475-481.

Kim, S.K. (2013), A randomized, controlled study of the effects of art therapy on older Korean-Americans' healthy aging, The Arts in Psychotherapy 40: 158-164.

Lara, J. et al. (2013), Towards Measurement of the Healthy Ageing Phenotype in LifestyleBased Intervention Studies, Maturitas 76: 189-199. 
Li, X.H. et al. (2012), Urban sustainability and human health in China, East Asia and Southeast Asia, Current Opinion in Environmental Sustainability 4: 436-42.

Marmot, M., J. Allen and P. Goldblatt (2010), A social movement, based on evidence, to reduce inequalities in health, Social Science and Medicine 71: 1254-1258.

Marmot, M. and R. Bell (2012), Plenaries. Fair society, healthy lives, Public Health 126: S4-S10.

Maasoumi, E. and T. Hu (2015), Weights and substitution degree in multidimensional wellbeing in China, Journal of Economic Studies 42(1): 4-19.

Mohanty, S.K. (2014), Comment on Smith et al. "Healthy Ageing in China", The Journal of the Economics of Ageing 4: 44-45.

Qiu, J. (2007), In Context, Ticking time bomb faced by China's ageing population, The Lancet 6: 582-583.

Rasmussen, L.J. et al. (2011), Meeting Report. Ageing, Longevity and Health, Mechanisms of Ageing and Development 132: 522-532.

Sadler, J. (2005), Future Health Trends in Food and Drinks: growth opportunities in daily dosing, GI, heart health, right fats and food. London, UK: Business Insights Ltd.

Shneerson, C. et al. (2014), Supporting healthy ageing: Training multi-disciplinary healthcare students, European Journal of Integrative Medicine 6: 104-111.

Silva, M. and S. Correia (2014), Active Brain: Online Social Platform for Active and Healthy Ageing, Procedia Computer Science 27: 38-45.

Sixsmith, J. et al. (2014), Healthy ageing and home: The perspectives of very old people in five European countries, Social Science and Medicine 106: 1-9.

Shytthe, A. et al. (2011), Design, recruitment, logistics, and data management of the GEHA (Genetics of Healthy Ageing) project, Experimental Gerontology 46: 934-945.

Smith, J.P., J. Strauss and Y. Zhao (2014), Healthy Ageing in China, The Journal of Economics of Ageing 4: 37-43.

Subramanyan, M.A., I. Kawachi and S.V. Subramanian (2010), Reactions to Fair Society, Healthy Lives (The Marmot Review), Social Science and Medicine 71: 1221-1222.

Vanhooren, V. et al. (2009), N-glycan profiles as tools in diagnosis of hepatocellular carcinoma and prediction of healthy human ageing, Mechanisms of Ageing and Development 130: 92-97.

Wang, X.Q. and P.J. Chen (2014), Correspondence, Population ageing challenges health care in China, The Lancet 383: 87.

Willcox, D.C., G. Scapagnini and B.J. Willcox (2014), Healthy aging diets other than the Mediterranean: A focus on the Okinawan die', Mechanisms of Ageing and Development 136-137: 148-162. 
Zhao, M., Y. Konishi and P. Glewwe (2013), Does information on health status lead to a healthier lifestyle? Evidence from China on the effect of hypertension diagnosis on food consumption, Journal of Health Economics 32: 367-385.

Zhao, Y., J.P. Smith and J. Strauss (2014), Can China aged healthily? Comment, The Lancet 384: 723-724. 
Table 2: Population aged 60+, 65+ and 80+ years by sex, major areas and regions (in 1,000 and percentages) (2013)

\begin{tabular}{|c|c|c|c|c|c|c|c|c|c|c|c|c|c|}
\hline & \multicolumn{3}{|c|}{$60+$} & \multicolumn{3}{|c|}{$65^{+}$} & \multicolumn{3}{|c|}{$80+$} & \multicolumn{3}{|c|}{ Dependency ratio } & \multirow{2}{*}{$\frac{\text { Old-age }}{\text { Support }}$} \\
\hline $\begin{array}{l}\text { Regions/ } \\
\text { Country groups }\end{array}$ & Total & Male & Female & Total & Male & Female & Total & Male & Female & Total & Child & $\begin{array}{l}\text { Old- } \\
\text { age }\end{array}$ & \\
\hline Africa & 60,033 & 27,428 & 32,606 & 38,513 & 17,212 & 21,302 & 5,248 & 2,127 & 3,121 & .. & & .. & .. \\
\hline$\%$ & 5.4 & 4.9 & 5.9 & 3.5 & 3.1 & 3.8 & 0.5 & 0.4 & 0.6 & 79.7 & 73.5 & 6.2 & 16.0 \\
\hline Asia & 468,549 & 233,015 & 245,535 & 307,699 & 142,585 & 165,115 & 57,576 & 23,609 & 33,967 & .. & .. & .. & .. \\
\hline$\%$ & 10.9 & 10.1 & 11.7 & 7.2 & 6.5 & 7.9 & 1.3 & 1.1 & 1.6 & 46.9 & 36.4 & 10.5 & 9.5 \\
\hline Europe & 169,874 & 70,951 & 98,926 & 125,152 & 50,332 & 74,823 & 33,239 & 11,025 & 22,216 & .. & .. & .. & .. \\
\hline$\%$ & 22.9 & 19.8 & 25.7 & 16.9 & 14.1 & 19.4 & 4.5 & 3.1 & 5.8 & 48.0 & 23.1 & 24.9 & 4.0 \\
\hline Latin America & 65,491 & 29,341 & 36,150 & 44,694 & 19,595 & 25,099 & 9,721 & 3,813 & 5,908 & .. & .. & .. & .. \\
\hline$\%$ & 10.6 & 9.7 & 11.5 & 7.2 & 6.5 & 8.0 & 1.6 & 1.3 & 1.9 & 51.8 & 40.8 & 11.0 & 9.1 \\
\hline North America & 70,571 & 31,836 & 38,736 & 50.041 & 21,990 & 28.052 & 13,311 & 5.008 & 8.304 & .. & .. & .. & .. \\
\hline$\%$ & 19.9 & 18.2 & 21.5 & 14.1 & 12.6 & 15.6 & 3.7 & 2.9 & 4.6 & 50.0 & 28.9 & 21.1 & 4.7 \\
\hline Oceania & 6,109 & 2,868 & 3,241 & 4,360 & 2,008 & 2,351 & 1,105 & 442 & 663 & .. & .. & .. & .. \\
\hline$\%$ & 15.9 & 15.0 & 16.9 & 11.4 & 10.5 & 12.3 & 2.9 & 2.3 & 3.5 & 54.4 & 36.8 & 17.6 & 5.7 \\
\hline World MDR & 287,020 & 123,611 & 163,414 & 211,051 & 87,901 & 123,154 & 56,879 & 19,723 & 37,158 & .. & .. & .. & .. \\
\hline$\%$ & 22.9 & 20.3 & 25.4 & 16.8 & 14.5 & 19.1 & 4.5 & 3.2 & 5.8 & 49.9 & 24.6 & 25.3 & 4.0 \\
\hline World LDR & 553,608 & 261,828 & 281,781 & 359,409 & 165,821 & 193,588 & 63,321 & 26,301 & 37,020 & .. & .. &.. &.. \\
\hline$\%$ & 9.4 & 8.7 & 10.0 & 6.1 & 5.5 & 6.7 & 1.1 & 0.9 & 1.3 & 52.4 & 43.1 & 9.3 & 10.8 \\
\hline World LDC & 48,580 & 22,918 & 25,662 & 31,654 & 14,761 & 16,893 & 4,515 & 2,034 & 2,481 & .. & .. & .. & .. \\
\hline$\%$ & 5.4 & 5.1 & 5.7 & 3.5 & 3.3 & 3.8 & 0.5 & 0.5 & 0.6 & 77.2 & 70.9 & 6.2 & 16.0 \\
\hline World & 840,628 & 385,439 & 455,194 & 570,459 & 253,722 & 316,742 & 120,199 & 46,024 & 74,178 & .. & .. & .. & .. \\
\hline$\%$ & 11.7 & 10.7 & 12.8 & 8.0 & 7.0 & 8.9 & 1.7 & 1.3 & 2.1 & 52.0 & 39.9 & 12.1 & 8.3 \\
\hline & & & & & & & & & & & & & \\
\hline
\end{tabular}

Source: Extracted from World Population Ageing (2013)

Note: More (MDR) and less (LDR) developed regions and least (LDC) developed countries. 
Table 7: Development of selected income, resources and investment measures in China (1990-2013)

\begin{tabular}{|c|c|c|c|c|c|c|c|c|c|c|c|c|c|}
\hline & \multicolumn{6}{|c|}{ Per capita: } & \multicolumn{2}{|c|}{ Investment in: } & \multicolumn{2}{|c|}{ Transportation: } & \multirow[b]{2}{*}{$\begin{array}{c}\text { Internet } \\
\text { Number } \\
\text { of users, } \\
\text { in } \\
10,000\end{array}$} & \multicolumn{2}{|c|}{ Welfare } \\
\hline Year & $\begin{array}{l}\text { Disposa } \\
\text { ble } \\
\text { income, } \\
\text { urban, } \\
\text { RMB }\end{array}$ & $\begin{array}{l}\text { Dispos } \\
\text { able } \\
\text { income } \\
\text {, rural, } \\
\text { RMB }\end{array}$ & $\begin{array}{c}\text { Water } \\
\text { use in } \\
\text { CuM }\end{array}$ & $\begin{array}{c}\text { Energy } \\
\text { consu } \\
\text { mption } \\
\text {, kg of } \\
\text { SCE }\end{array}$ & $\begin{array}{c}\text { Floor } \\
\text { space, } \\
\text { urban } \\
\text {, m2 }\end{array}$ & $\begin{array}{c}\text { Floor } \\
\text { space, } \\
\text { rural, } \\
\text { m2 }\end{array}$ & $\begin{array}{l}\text { Treatment } \\
\text { of } \\
\text { industrial } \\
\text { pollution, } \\
\text { in } 10,000 \\
\text { yuan }\end{array}$ & $\begin{array}{c}\text { Fixed } \\
\text { assets, } \\
\text { in } 100 \\
\text { million } \\
\text { yuan }\end{array}$ & $\begin{array}{l}\text { Passeng } \\
\text { er km, } \\
\text { total }\end{array}$ & $\begin{array}{c}\text { Civil } \\
\text { vehicles } \\
\text {, in } \\
10,000\end{array}$ & & $\begin{array}{c}\text { Basic } \\
\text { pension, } \\
\text { in } \\
10,000 \\
\text { persons }\end{array}$ & $\begin{array}{c}\text { Health } \\
\text { personn } \\
\text { el }\end{array}$ \\
\hline 2000 & 6,280 & 2,253 & 435 & 123.7 & .. & 24.8 & $2,347,895$ & 32,918 & 12,261 & 1,609 & 2,250 & 13,617 & 159,212 \\
\hline 2001 & 6,860 & 2,366 & 438 & 127.2 & & 25.7 & $1,745,280$ & 37,214 & 13,155 & 1,802 & 3,370 & 14,182 & 165,855 \\
\hline 2002 & 7,703 & 2,476 & 429 & 134.0 & 24.5 & 26.5 & $1,883,663$ & 43,500 & 14,126 & 2,053 & 5,910 & 14,737 & 175,444 \\
\hline 2003 & 8,772 & 2,622 & 413 & 153.4 & 25.3 & 27.2 & $2,218,281$ & 55,567 & 13,811 & 2,383 & 7,950 & 15,507 & 183,103 \\
\hline 2004 & 9,422 & 2,936 & 428 & 175.7 & 26.4 & 27.9 & $3,081,060$ & 70,477 & 16,309 & 2,694 & 9,400 & 16,353 & 192,611 \\
\hline 2005 & 10,493 & 3,255 & 432 & 194.1 & 27.8 & 29.7 & $4,581,909$ & 88,774 & 17,467 & 3,160 & 11,100 & 17,488 & 199,734 \\
\hline 2006 & 11,759 & 3,587 & 442 & 211.8 & 28.5 & 30.7 & $4,839,485$ & 109,998 & 19,197 & 3,697 & 13,700 & 18,766 & 206,958 \\
\hline 2007 & 13,786 & 4,140 & 441 & 233.8 & 30.1 & 31.6 & $5,523,909$ & 137,324 & 21,593 & 4,358 & 21,000 & 20,137 & 214,748 \\
\hline 2008 & 15,781 & 4,761 & 446 & 240.8 & 30.6 & 32.4 & $5,426,404$ & 172,828 & 23,197 & 5,100 & 29,800 & 21,891 & 223,623 \\
\hline 2009 & 17,175 & 5,153 & 448 & 258.3 & 31.3 & 33.6 & $4,426,207$ & 224,599 & 24,835 & 6,281 & 38,400 & 23,550 & 233,553 \\
\hline 2010 & 19,109 & 5,919 & 450 & 278.3 & 31.6 & 34.1 & $3,969,768$ & 251,684 & 27,894 & 7,802 & 45,730 & 35,984 & 241,156 \\
\hline 2011 & 21,810 & 6,977 & 454 & 278.3 & 32.7 & 36.2 & $4,443,610$ & 311,485 & 30,984 & 9,356 & 51,310 & 61,573 & 250,258 \\
\hline 2012 & 24,565 & 7,917 & 455 & 293.8 & 32.9 & 37.1 & $5,004,573$ & 374,695 & 33,383 & 10,933 & 56,400 & 78,796 & 258,283 \\
\hline 2013 & 26,955 & 8,896 & 456 & & .. & .. & $8,676,647$ & 446,294 & 27,572 & 12,670 & 61,758 & 81,968 & \\
\hline 2013/2000a & 4.292 & 3.949 & 1.048 & 2.375 & 1.343 & 1.496 & 3.696 & 13.558 & 2.249 & 7.874 & 27.448 & 6.020 & 1.622 \\
\hline
\end{tabular}

Source: China Statistical Yearbook (2014).

Note: 'a' indicates alternative ratio of the most recent period to the earliest period available. 